\title{
. \\ The rise of consumerism and the localization of trademark design in colonial Korea: Focusing on the "cultural rule" period between 1920 and 1937
}

\author{
Yongkeun Chun / Royal College of Art / London / UK \\ Min-Soo Kim / Seoul National University / Seoul / Korea
}

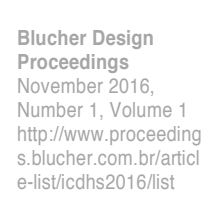

\begin{abstract}
This study aims to capture aspects of localization in trademark design during the so called "cultural rule" period (1920-1937) in colonial Korea. While conducting case studies of corporate and merchandise trademarks, it also pays attention to political, social and economic conditions, as the shift of policy by the colonial government in 1920 led to the expansion of media, commerce and advertising, resulting in the rise of modern consumerism in Korea. In trademark design, a "Korean transformation" was observed. National icons were adopted to emphasize the origin of Korean products and companies, original forms of symbolization were sought as counterparts to the Japanese family crest style, and the use of hangeul (Korean characters) expanded. This article claims that although nationalist implications were imbedded in these changes, the fundamental driving force was the profit motive of enterprises, which sought optimized forms to attract the attention of consumers.
\end{abstract}

\section{Keywords}

Trademark design, visual identity, consumerism, Korean design history, colonial Korea

\section{Introduction}

As an institution that gathers capital, produces goods and creates profits on a large scale, the corporation is an entity that characterizes the modern economy. Moreover, if we accept the fact that the company is a modern organization, it could be said that the characteristics of the modernization of a certain society would be imbedded in the activities and appearances of the companies within it. Therefore, as visual representations of corporations and their products that are put out on the front line, it could also be assumed that contemporary social and cultural traits are reflected in trademarks.

This is especially true in the case of Korea between the late 1800 s and early 1900 s, as the concept and system of modern commerce, as well as mass advertising and the graphic symbolization of its components, were all introduced as part of an explicitly "modern" civilisation. The emergence and establishment of the trademark in Korea were largely lead by foreign companies operating in the Korean market after the opening of the ports in 1876. At the beginning of the twentieth century, among the foreign powers surrounding Korea, the Japanese gradually enhanced their political and economical influence, dominating the Korean consumer goods market. As a result, during the first twenty years or so in Korea, advertising as a whole, and trademark design in particular, tended to follow the Japanese convention with little modification. It was mainly from the 1920s that changes, which could be described as "reactions" to the initial foreign introduction of trademark design, became significant among Korean firms. In other words, a tendency to "localize" trademark design was apparent, and this was influenced by a shift in social atmosphere and the raised commercial awareness of the public.

\section{The "cultural rule" and the rise of a modern consumerism}

The March First Movement in 1919, a nationwide protest against the Japanese occupation, made the colonial government realize that excessive oppression of the Korean public would act against its interests, destabilizing colonial 
rule. Consequently, the so called "cultural rule (munhwa jeongchi)" was proclaimed in 1920, which promised greater opportunities for Koreans and the Japanese respect for Korean culture (Peattie, 1988). Although the fundamental intention was to stabilize and extend their domination by conciliating the Koreans and creating class that supported the colonization (Kang, 1994), nevertheless, under this scheme, which continued until the initiation of "general mobilization" in 1938, public conditions were amended to a certain degree as the colonial government broadly alleviated social and economic regulations. Moreover, as Robinson (1998) has demonstrated in his study of radio broadcasting in Korea, the "cultural rule" provided a space for Koreans to develop the vernacular culture in constructing a modernity of their own, which acted to both sustain and subvert the assimilation policy.

With regards to trademark design, changes in economic and media policies are of particular significance, as they laid a foundation for the maturation of modern consumerism. In 1920, the colonial government abolished the legislation that suppressed the establishment of private companies (Hoesaryeong) (Jeon, 2012), and exempted Japan-made industrial goods from import duties (Seoulteukbyeolsisa-pyeonchan-wiwonhoe, 2003). These decisions drastically accelerated the inflow of Japanese capital and commodities, while partly facilitating the organization of business by Koreans as well. On the other hand, permission to publish newspapers was granted to the private sector, which resulted in the foundation of three Korean newspapers, growth of the overall volume of daily media, and the expansion of the reader class among Koreans (Kim, 2002).

With the support of the colonial government, investment in Korea by Japanese entrepreneurs was invigorated, which was also evident in the retail industry. From around the mid-1920s, Japanese retailers such as Chōjiya, Minakai and Mitsukoshi expanded their business in Seoul by increasing capital investment or constructing new buildings, and re-established themselves as "department stores" (baekhwajeom) (Oh, 2004). "Modern" commodities imported from Japan filled these newly established spaces for consumption, and consumer culture in Korea was formed around these products. According to Hwang (2006), by 1930, the formation of a massconsumer society was evident in Korea with Seoul as the center. In other words, a "modern" consuming public had emerged, who dedicated a certain amount of time for shopping, and who had acquired the skills to express themselves through their consumption. Of course, it should be noted that the enjoyment of this material affluence was limited to the upper class urbanites, who were only a small part of the population. Nevertheless, a system of massconsumption existed, where consumers, companies and products interacted, and advertising worked as a device that mediated this circulation.

Meanwhile, the expansion of print media naturally provided more space for advertising, which was taken up by "big brands" of Japanese origin, such as Ajinomoto, Kaō and Mitsuwa. Because the 1920s was a period when Japanese manufacturers strived for the improvement of advertising in their own market, together with the importation of these major Japanese products, the developments that had been made in Japanese print advertising design were introduced to Korea as well. In particular, a consistent and integrated representation of visual brand identities was significant.

The tendency to emphasize brand identities in advertisements, in turn, seems to have elevated the public awareness of trademarks in Korea. For example, a newspaper article from 1922 which depicted the daily

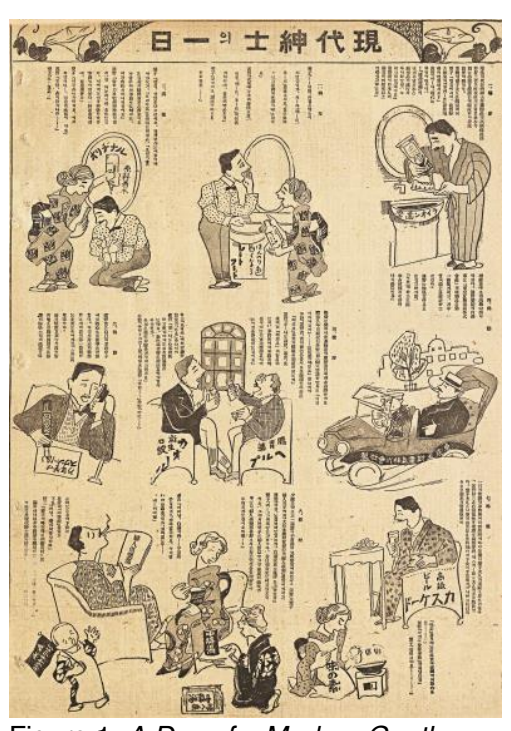

Figure 1: A Day of a Modern Gentleman (Maeilsinbo, 25 May 1922) routine of a "modern gentleman," filled with major Japanese products and their logos, was representative of the widespread popularity of these branded commodities. In addition, a "Trademark Exhibition" was held in 1922, and a series of articles which presented and explained the trademark designs of twenty-nine companies in Seoul was featured in Maeilsinbo in 1927. These examples point to the fact that the brand had become more important to the Korean consumers, not only in its name, but also in its visual aspects. Along with the rise of modern consumerism in Korea, this increased public interest towards trademarks and their design led companies to devote more efforts to perfecting their visual identity. In the process of such elaboration, especially among Korean companies who had to survive competition with their counterparts from the empire, a tendency to "Koreanize" the designs was observed, which could be divided into three different aspects.

\section{The Mulsanjangryeo movement and symbols of "ours"}

While the society enjoyed a relative abundance of commodities after 1920, the 
economic stability and independence of Koreans still remained an issue under the colonial capitalism. As a means to overcome this situation, the Mulsanjangryeo (Korean Products Support) Movement, an economic independence movement was initiated by nationalist-capitalists in 1923, and was aimed at the accumulation of Korean capital by promoting the consumption of locally produced goods (S. R. Lee, 2005). Under the influence of this movement, Korean merchants and manufacturers made advertisements that strongly provoked national sentiment, and trademarks were also designed according to the general slogan of the campaign, "our products." In order to represent products of Korean origin, familiar national icons were transformed into trademarks. For instance, the map of the Korean Peninsula was used as an emblem of national territory that ought to be protected, and the Geobukseon (Turtle Ship) appeared as a protest against the Japanese, imbued with the meaning of a patron that defended the nation from Japanese invasion several centuries ago.

The most explicit example of this patriotic representation strategy is seen in the case of Taegeukseong (ying-yang and stars) brand of cotton cloth. (Figure 2) The taegeuk, or the Korean ying-yang, used as the central motif in the Korean flag from the late 1800s onwards, has been perceived as a symbol of national identity ever since. However, during the Japanese occupation, and especially after the March First Movement, public exposure of the motif became difficult as it was censored by the colonial police. Therefore, using the taegeuk in the brand name and as a trademark, and displaying "this trademark, our cloth, our pride" in advertisements, made a bold statement that directly stimulated the patriotic spirit of Korean consumers. The campaign was successful, in that Taegeukseong cotton became widely perceived as "our product," leading to a rapid increase in sales. In similar cases, by displaying strong Korean motifs as trademarks, products and corporations could put on a patriotic image, and the fact that this strategy was effective also indicates that consumers keenly reacted to the message implied in the graphic symbol.

Regarding the actual achievements of the Mulsanjangryeo Movement, however, economic historians have pointed out that it failed to fulfill the missions it had proclaimed. In fact, despite ostensibly emphasizing economic independence and national identity, many of the major companies who led this movement were highly cooperative with the colonial government's control policies (Bang, 2010). Thus, it is worth noting that even while the nationalist values represented through the trademark were actually void, the trademark still was a valid trick of trade, and this seems to reflect the ironical situation of the colonial capitalism.

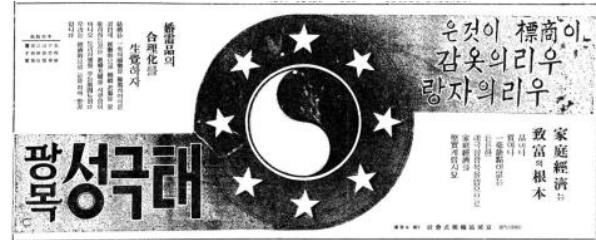

Fig. 2: Taegeukseong brand presented in a newspaper advertisement (Dongailbo, 14 Nov 1933

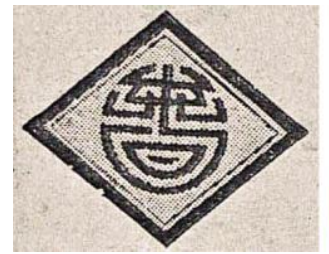

Fig. 3: Trademark of Joseon-maeyak-hoesa (left) and gilsangmun$j a$ in traditional fabrics
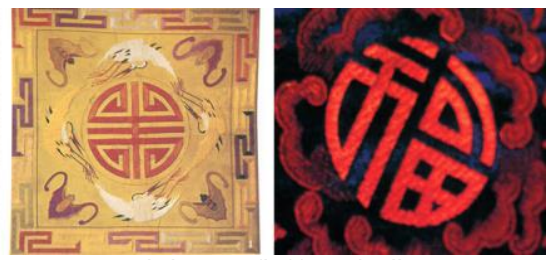

and gilsangmun-

\section{A search for an original form of symbolization}

During the 1910s, the Japanese family crest style was established as a standard for corporate trademarks in Korea. Entering the 1920s, as the culture around trademark design matured, Korean companies started to differentiate their symbols by modifying them into a style that was more familiar to the local visual culture. Generally, the use of letters became prevalent as they replaced figurative elements, and these could be divided into two types.

The first type was represented by the frequent use of stylized Chinese characters, which means letters that are highly distorted to fit a geometrical frame, distinct from ordinary legible letterforms. A typical example is the corporate trademark of the Korean pharmaceutical company, Joseon-maeyak-hoesa. (Figure 3 ) The logo is a combination of two characters "hoe (回)" and "chun (春)" inside a diamond shape, transformed to the extent that both are barely decipherable. The result is a design that is perceived as a pattern rather than as letters. The origin of these distorted letterform designs can be found in the gilsangmunja, which are lucky Chinese characters stylized within typically round or rectangular figures, applied to everyday objects such as ceramics, clothing and furniture. The gilsangmunja, as one sort of the munjamun (letter patterns) tradition prevalent from the Joseon Dynasty, were forms of visual symbolization comprehensible to the Korean public. (Lim, 2004)

Another distinctive type of the letter trademark is the pattern constructed by the radial repetition of characters. (Figure 4) This design was commonly found in trademarks of enterprises with simple and symmetrical 
Chinese characters in their names. Although this style seems to originate from Japanese corporate identity design, the fact that it is found in a much larger proportion of Korean firms is intriguing. Arguably, it can be seen as a compromise, following the tradition of munjamun on one hand, and selectively adopting a specific design technique from the Japanese family crest that suited the local visual culture on the other.

Although the Japanese family crest had been accepted as a typical form of corporate trademark in the 1910s, its visual grammar was unique to Japan, and contained symbols such as plants, animals or architectural elements, not something that could readily be comprehended by the Korean public. In the case of Korean firms these alien elements remained peripheral or merely decorative, making it difficult to imbue meanings or values, which in fact is the essential function of a trademark. Consequently, as the public became more aware of trademarks in the 1920s, these graphic components, which were invalid as a visual language, had been partly discarded from the logos of Korean companies. Instead, applying munjamun, a local tradition of styling, or combining it with a foreign technique, had become valid design methods. Therefore, it could be said that at this point, the search for original forms of symbolization had been extensively explored within the Korean trademark culture.

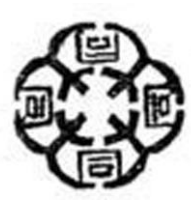

Fig. 4: Trademark designs with radially repeated letters
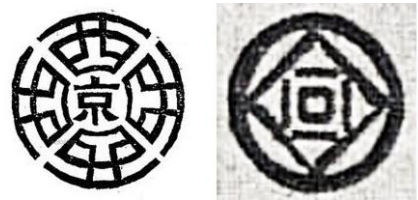

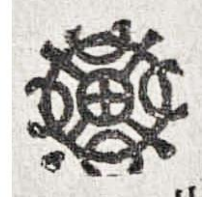

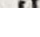

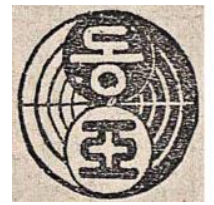

Fig. 5: Hangeul logos of Donga-buin-sanghoe (left, Maeilsinbo, 5 Jan 1927) and Dongyangjeo Fabric (right, Dongailbo, 6 May 1928 and 3 May 1929)

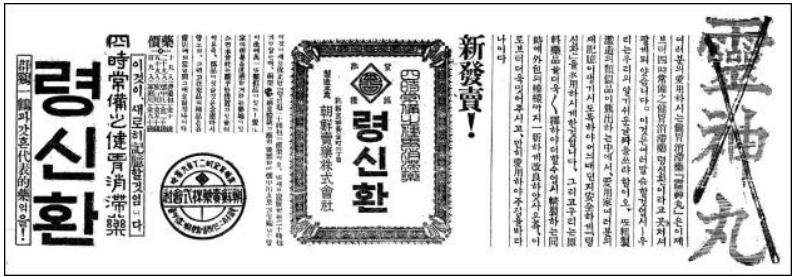

Fig. 6:Trademark renewal advertisement of Ryeongsinhwan (Dongailbo, 20 Sep 1922)

\section{The expansion of hangeul trademarks}

Hangeul trademarks were not completely new in the field of corporate identity, as they had been used within the Japanese family crest style as components, to substitute Chinese or Japanese characters during previous years. However, as the localization of trademarks proceeded throughout the 1920s and 1930s, the use of hangeul in the designs had become more frequent, not only among

Korean but also Japanese companies, and within various contexts.

Since hangeul had long been considered as the essence of Korean culture and spirit, it was often used as a symbol of patriotism. The logos of Donga-buin-sanghoe and Dongyangjeo Fabric, brands that were closely related to the Mulsanjangryeo Movement mentioned above, were representative examples, featuring their names in hangeul within the trademarks. (Figure 5) The intention was similar to the case of Taegeukseong, used within advertisements to emphasize the nationality of the business.

Meanwhile, the increased use of hangeul trademarks within the Korean rubber industry around 1925 was also remarkable. As a rare case in this colonial situation, rubber production was a field where Korean firms were superior to their Japanese counterparts in both quality and quantity (S. R. Lee, 1990). Thus, in this case, although adopting national characters in the trademark was not directly an act of patriotism, it was a means of reaffirming and promoting the industrial superiority of Korean companies.

The most prominent property of the hangeul trademark, however, was its legibility. The case of

Ryeongsinhwan, a leading Korean digestive medicine brand, best illustrates this utilitarian approach to using local characters in the logo design. In 1922, the brand announced the change of its famous trademark from a Chinese logotype to Korean, through newspaper advertisements. In the introduction of their brand renewal, it was clearly stated that a hangeul logotype had been chosen as it was "comprehensible," and would prevent consumers from confusing it with fake or similar brands. (Figure 6) Since most of its competitors were also Korean, it could be assumed that there was little intention to promote the product's national identity by the use of Korean script. The fact that hangeul was applied to trademarks mostly because it was legible, can also be inferred from its use by Japanese firms advertising in Korea. Hangeul logotypes for Japanese brands were mostly created as part of localized marketing campaigns. For example, advertisements featuring illustrations of Japanese women wearing kimonos, had been changed to women wearing hanbok (Korean dress), in which case the brand names and trademarks were also translated into Korean. (Figure 7) As in the case of Ryeongsinhwan, the translational conversion of logotypes 


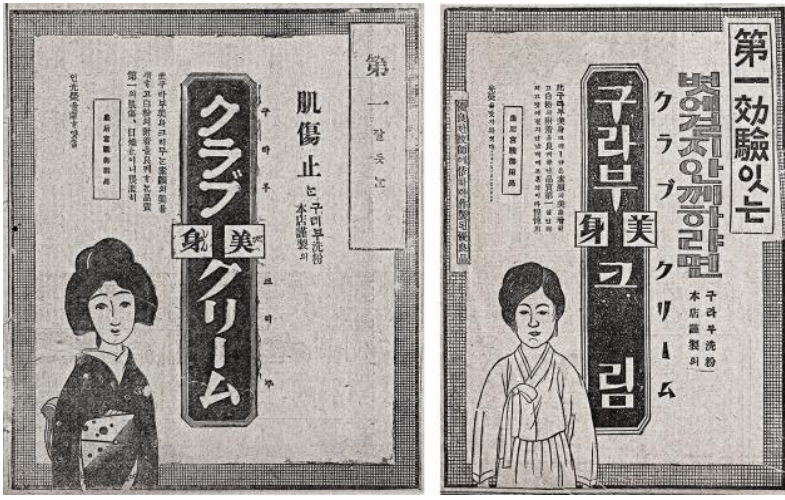

Fig. 7: Localized advertisements and trademarks of Kurabu Cosmetics (Maeilsinbo, 12 Jan 1921 and 4 Aug 1925) was beneficial in terms of the likelihood of comprehension. Here, as noted by G. R. Lee (2001), the issue of national identity was deferred; instead, by trying to find a form of design that could be inscribed on the minds of a broader public, economic logic gained significance.

\section{Conclusion}

Trademark design in colonial Korea appeared as a complex and hybrid phenomenon, where the policies of the colonial government, traditions in Korean visual culture, the perception of the consumer and profit motives of both Korean and Japanese entrepreneurs acted upon each other. The "Korean transformation" in trademark

design during the 1920s and 1930s was a course of visual elaboration, in order to influence Korean consumers who had now become more brand-sensitive. This holds significance, as the effort to apply local specificity to the imported "modern" commercial symbolization system was observed on an industrial scale for the first time. Within the political and economical conditions of the colony, experiments were conducted with graphic elements having a sense of locality, such as national icons, traditional patterns and local characters. However, behind all these experiments lay the fundamental principle of profit, trying to capture the interest of the potential customers to the maximum.

\section{References}

Bang, G. J. (2010). Geundae han-guk-eui minjokjueui gyeongje sasang. Seoul: Yonsei University Press. Hwang, J. Y. (2006). Samil Undong-gwa modeon laipeu. In Y. S. Kim (Ed.), Han-guk misul 100 nyeon. Paju: Hangilsa.

Jeon, U. Y. (2012). Han-guk hoesaeui tansaeng. Seoul: Seoul National University Press.

Kang, C. I. (1994). Ilje-eui Joseon jibae jeongchaeck. Yeoksawa Hyeonsil(12), 34-67.

Kim, M. H. (2002). Han-guk eonronsa. Seoul: Nanam.

Lee, G. R. (2001). Iljesidae gwanggowa jegugjuui. Misulsanondan, 12, 127-148.

Lee, S. R. (1990). Iljeha joseonin gomugongeobjabon. Yeoksawa Hyeonsil, 3, 219-268.

Lee, S. R. (2005). Iljepasijeumgi joseonin jabongaui hyeonsil insiggwa daeeung. Yeoksawa Hyeonsil, 67, 166-206.

Lim, Y. J. (2004). Hanguk-eui jeontong munyang. Seoul: Daewonsa.

Oh, J. S. (2004). Iljeha baeg-hwajeom eobgyeui dong-hyang-gwa gwan-gyeindeului saeng-hwalyang-sig. In Yonsei University Gukhak Yeon-guwon (Ed.), Iljeui sigminjibaewa ilsangsaeng-hwal: Hyean.

Peattie, M. R. (1988). The Japanese Colonial Empire, 1895-1945. In P. Duus (Ed.), The Cambridge History of Japan. Cambridge: Cambridge University Press.

Robinson, M. (1998). Broadcasting in Korea, 1924-1937: Colonial Modernity and Cultural Hegemony. In S. Minichiello (Ed.), Japan's Competing Modernities: Honolulu: University of Hawai ‘I Press.

Seoulteukbyeolsisa-pyeonchan-wiwonhoe. (2003). Seoul sang-gong-eobsa: Seoulteukbyeolsisapyeonchan-wiwonhoe.

\section{Biographical note}

Yongkeun Chun is an MPhil student in the History of Design programme, Royal College of Art. He completed his MFA in Design History and Culture at Seoul National University. His current research explores the relationship between Japanese 'commercial art (shōgyō bijutsu)' and commercial graphic design in Korea during the Japanese occupation.

Min-Soo Kim, Professor and Director of Design History and Cultural Studies, graduate course of Seoul National University(www.snu-dhc.com); Received Ph.D from New York University in USA.; Former chief editor of The Journal of Design Culture and Criticism (JDCC, 1999 2002), the first journal of cultural history, theory and criticism on design in Korea. 